\title{
The Effect of Glucose-Dependent Insulinotropic Polypeptide Infused at Physiological Concentrations on the Release of Insulin in Man
}

\author{
D. L. Sarson, S. M. Wood, D. Holder* and S. R. Bloom \\ Department of Medicine, Royal Postgraduate Medical School, London, UK
}

Summary. Blood glucose and the responses of insulin and glucose-dependent insulinotropic polypeptide (GIP) were measured in 12 healthy, normal weight subjects after drinking $50 \mathrm{~g}$ glucose. On a subsequent occasion each subject was given a simultaneous infusion of GIP and glucose to mimic the plasma concentrations observed in the first test. The peak GIP concentration after oral glucose was $22.3 \pm 1.9 \mathrm{pmol} / 1$ (mean $\pm \mathrm{SEM}$ ), but was higher after GIP infusion at $36.3 \pm 4.6 \mathrm{pmol} / \mathrm{l},(p<0.005)$. The blood glucose levels following oral glucose peaked at 6.3 $\pm 0.5 \mathrm{mmol} / 1$ which was the same as seen after intravenous glucose. The insulin response to oral glucose was, however, far higher $(431.3 \pm 58.2 \mathrm{pmol} / 1)$ than that obtained after GIP and glucose infusion (191.6 $\pm 30.9 \mathrm{pmol} / 1, p<0.001)$. Thus it has not proved possible to explain completely the oral enhancement of insulin release by the action of GIP alone.

Key words: Glucose-dependent insulinotropic polypeptide, gastric inhibitory polypeptide (GIP), insulin, blood glucose, enteroinsular axis, incretin.

Gastric inhibitory polypeptide, now commonly referred to as glucose-dependent insulinotropic polypeptide (GIP) is released by cells present in the upper small intestine in response to oral but not intravenous glucose [1]. It has been shown that GIP potentiates the release of insulin [2], but this is only demonstrable when glucose is elevated [3]. The evidence in support of this hormone playing a major part in the enteroinsular axis has been the subject of a recent review [4]. This study was designed to investigate the effect of

* Present address: Barnet General Hospital, Wellhouse Lane, Barnet, Herts, UK
GIP on insulin release in the presence of physiological hyperglycaemia, as seen after a $50 \mathrm{~g}$ oral glucose load in healthy subjects.

\section{Subjects and Methods}

\section{Subjects}

The experiments were performed on 12 healthy volunteers (eight males and four females, mean weight $68.6 \pm 3.2 \mathrm{~kg}$, mean age 25.8 years, range $18-46$ years). Informed consent was obtained from each subject, none of whom were taking any medication. Approval for the infusion of GIP was obtained from the Hammersmith Hospital Ethical Committee. Before investigation all subjects had been maintained on a normal unrestricted diet.

\section{Test Protocols}

Subjects were studied in a recumbent position after an overnight fast. Venous access was provided by $19 \mathrm{G}$ indwelling catheters, separate arms being used for infusion and blood sampling.

Oral glucose: blood samples were taken before and for $120 \mathrm{~min}$ after ingestion of $50 \mathrm{~g}$ glucose, dissolved in $150 \mathrm{ml}$ water.

Intravenous glucose and GIP infusion: both glucose and GIP were administered from syringes placed in separate, variable rate, constant speed syringe ram pumps (Harvard Instruments, Massachusets, USA). Glucose was given as $10 \%$ dextrose in $0.9 \%$ saline for $60 \mathrm{~min}$. The rate of infusion was adjusted according to the capillary glucose concentration of samples taken from a warmed hand. The concentration of glucose was estimated by using glucose oxidase strips (Dextrostix, Ames, Bucks) and a portable photometer (Hypocount, Hypoguard, Suffolk). Information derived in this way was used to approximate the glucose curve obtained after oral glucose. The amount of glucose given varied according to the individual within a range of $10-18 \mathrm{~g}$.

Pure porcine GIP (Professor J.C. Brown, Vancouver, Canada) was made up in $0.15 \mathrm{~mol} \mathrm{NaCl} / 1$ and $0.3 \mathrm{mmol}$ human serum albu$\mathrm{min} / 1$ (Lister Blood Products Laboratories, Elstree, Herts, UK) and administered as a $30 \mathrm{~min}$ infusion of $0.4 \mathrm{pmol} \mathrm{kg}^{-1} \mathrm{~min}^{-1}$, followed by a $30 \mathrm{~min}$ infusion of $0.1 \mathrm{pmol} \mathrm{kg-1} \mathrm{min}^{-1}$. This regimen had 


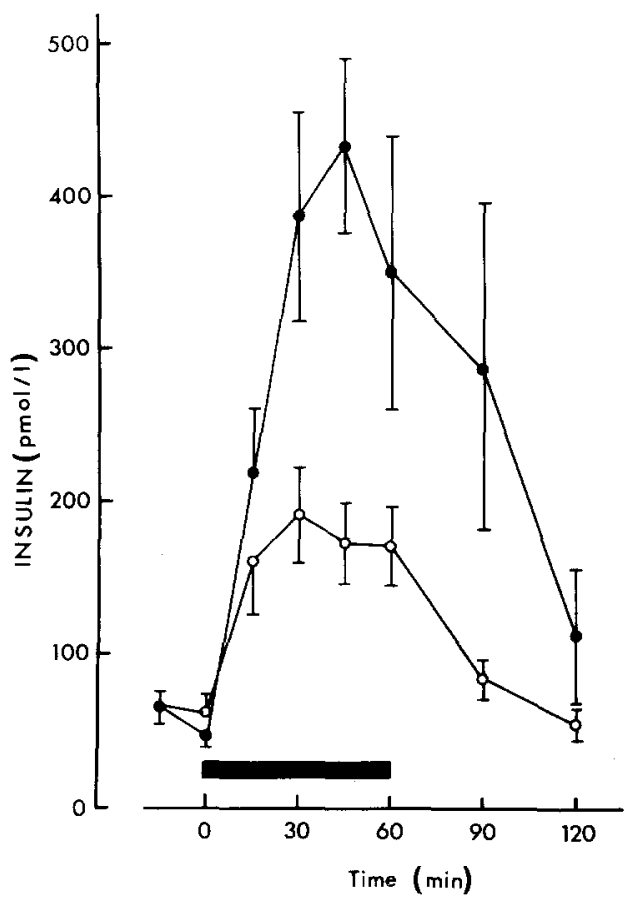

Fig. 1. Insulin response (pmol/1, mean \pm SEM) in 12 subjects following $50 \mathrm{~g}$ oral glucose $(-)$ or IV glucose + IV GIP (O). Solid bar denotes duration of infusion (see text for details)

been found, from a previous pilot experiment, to mimic approximately the plasma levels of GIP after a mixed evening meal. The infusion fluid was flushed through the system externally for $5 \mathrm{~min}$ to saturate the tubing. Samples of infusate were taken before and after each infusion dose to assess losses due to adsorption.

\section{Glucose and Hormone Estimations}

Blood glucose: $2.5 \mathrm{ml}$ whole blood was taken into fluoride oxalate tubes which were kept refrigerated $\left(+4^{\circ} \mathrm{C}\right)$ until measurement by a glucose oxidase method for use with an auto-analyser.

Hormone estimations: $10 \mathrm{ml}$ blood was taken into chilled lithium heparin tubes containing 1000 kallikrein inhibitory units (KIU) $/ \mathrm{ml}$ aprotinin (Trasylol, Bayer, FRG). This blood was immediately centrifuged for $5 \mathrm{~min}$ at $1600 \times \mathrm{g}$, the plasma decanted and stored deep frozen $\left(-20^{\circ} \mathrm{C}\right)$ until measurement in a single assay (per hormone) to minimise the influence of any interassay error.

Insulin was measured using ${ }^{125} \mathrm{I}$-labelled insulin (IM38: The Radiochemical Centre, Amersham, Bucks, UK) guinea-pig antiinsulin serum (Wellcome, Beckenham, Kent, UK) and human insulin standard (Wellcome, Beckenham, Kent, UK). Standard curve tubes were set up in human plasma cleared of endogenous insulin by charcoal adsorption. The incubation products were separated by dextran-coated charcoal. Sensitivity of the assay was $6 \mathrm{pmol} / 1$.

Estimation of GIP was performed by radioimmunoassay using a mid C-terminal reacting antiserum (GIP 19) raised in a rabbit using carbodiimide condensation of pure porcine GIP to haemocyanin [5]. Radiolabelled antigen $\left({ }^{125}\right.$ I GIP) was prepared by lactoperoxidase oxidation [6]. The specific activity was approximately $65 \mathrm{~Bq} / \mathrm{fmol}$. In the absence of added unlabelled GIP, the antiserum used at a final dilution of 1:96,000 bound approximately $50 \%$ of $1.5 \mathrm{fmol}$ of ${ }^{125} \mathrm{I}$ GIP added to each assay tube.
Standard curve plasma was prepared by the removal of endogenous GIP from human plasma by specific immuno-absorption [7]. Antiserum GIP 19 recognises two major immunoreactive forms of GIP. When analysed by gel permeation chromatography, the first peak elutes shortly after cytochrome $\mathrm{C}$ (Kav $0.3 \pm 0.02$, mean of five estimations), the other peak co-eluting with pure porcine standard (Kav $0.67 \pm 0.02$ ). The antibody demonstrated no crossreactivity with any other gastro-intestinal or pancreatic hormones with the exception of glucagon, where it was less than $1 \%$. The sensitivity of the assay allowed changes of $3 \mathrm{pmol} / \mathrm{I} \mathrm{GIP}$ to be detected between individual adjacent plasma samples with $95 \%$ confidence.

\section{Analysis of GIP Preparation for Infusion}

To validate the molecular integrity of the GIP preparation used in this study the following tests were carried out:

Gel permeation chromatography: samples of the infusate diluted in plasma were loaded onto a $60 \times 0.9 \mathrm{~cm}$ Sephadex G50 superfine column (Pharmacia, Uppsala, Sweden) and eluted at $5 \mathrm{ml} / \mathrm{h}$ with 0.1 mol formic acid/l. Dextran blue, Cytochrome $\mathrm{C}$ and $\mathrm{Na}{ }^{\mathrm{i} 25} \mathrm{I}$ were added to each run as internal markers of molecular size. Column calibration was carried out with $500 \mu$ l of human serum albumin to which 0.5 pmol pure porcine GIP and the internal markers were added at the beginning and end of the test. The column conditions remained stable throughout. All fractions collected were stored deep frozen and estimated in a single assay.

Disappearance half-time studies: six healthy volunteers received an infusion of $0.14 \mathrm{pmol} \mathrm{kg}^{-1} \mathrm{~min}^{-1}$ of GIP for $60 \mathrm{~min}$ followed by an infusion of $0.39 \mathrm{pmol} \mathrm{kg}^{-1} \mathrm{~min}^{-1}$ for a further $60 \mathrm{~min}$. Blood samples were drawn from the opposite arm at $1,3,5,7,9,11,13,16,19$, $21,24,27$ and $30 \mathrm{~min}$ after plateau concentrations of $102.6 \pm$ $5.5 \mathrm{pmol} / \mathrm{l}$ had been reached.

Parallelism with pure porcine standard: four batches of the infusion fluid, taken after each dose, were diluted serially to give nominal concentrations of $4,2.0,1.0$ and $0.5 \mathrm{pmol} / \mathrm{ml}$ and added to duplicate tubes interlocked with a standard curve under usual assay conditions.

\section{Statistical Analyses}

Results are expressed as mean and standard error of the mean ( \pm SEM, degrees of freedom $=n-1$ ). Where appropriate increments are denoted by $\Delta$. Significance of results was assessed using Student's paired ' $t$ ' test (two-tailed).

\section{Results}

The responses of insulin and GIP to both tests are shown in Figures 1 and 2 respectively. Following the oral glucose load, blood glucose rose from a mean basal of $4.1 \pm 0.4$ to $5.9 \pm 0.5 \mathrm{mmol} / 1(\Delta$ glucose $=1.80$ $\pm 0.6)$ at $30 \mathrm{~min}$ and reached a peak of $6.3 \mathrm{mmol} / 1(\Delta$ glucose $2.2 \pm 0.5)$ at $45 \mathrm{~min}$. Plasma insulin rose briskly to $387.8 \pm 69.1 \mathrm{pmol} / 1$ at $30 \mathrm{~min}$ and reached a peak of $431.3 \pm 58.2 \mathrm{pmol} / 1$ at $45 \mathrm{~min}$. Plasma GIP rose to a peak of $22.3 \pm 1.9 \mathrm{pmol} / 1$ at $30 \mathrm{~min}$.

During the combined glucose and GIP infusion blood glucose rose to $6.3 \pm 0.3 \mathrm{mmol} / 1$ at 30 and 
$45 \mathrm{~min}$ from a mean basal of $4.3 \pm 0.2 \mathrm{mmol} / 1(\Delta$ glucose $2.0 \pm 0.3$ ) which was similar to that reached after oral glucose. The insulin response, however, was much reduced during this test with concentrations of $191.6 \pm 30.9$ at $30 \mathrm{~min}(p<0.005)$ and $173.1 \pm 27.9$ at $45 \mathrm{~min}(p<0.001)$. The plasma GIP obtained from infusion, however, increased from a mean basal of 9.1 \pm 1.5 to $36.3 \pm 4.6 \mathrm{pmol} / 1$ at $30 \mathrm{~min}(p<0.005)$ and $26.3 \pm 2.4$ (NS versus oral glucose) at $45 \mathrm{~min}$.

The GIP used for infusion eluted as a single peak after gel permeation chromatography. The elution coefficient $\left(\mathrm{K}_{\mathrm{av}}\right)$ was $0.66 \pm 0.04$ which was the same as for human GIP from jejunal extracts, 5000 molecular weight GIP found in human plasma after oral glucose and porcine GIP from jejunal extracts; column recovery was $88 \pm 6 \%$. The disappearance half time $\left(t_{V 2}\right)$ of infused GIP in plasma was found to be $20.3 \pm$ $1.1 \mathrm{~min}$. The samples of infusate diluted in subject's plasma demonstrated full parallelism with the standard curve.

\section{Discussion}

Amongst the many gut factors proposed to exert incretin-like effects, the gut hormone GIP has become established as the main contender. In 1973 Dupre et al. [2] infused GIP to produce plasma levels of approximately $200 \mathrm{pmol} / 1$ and showed that this was potently insulinotropic when blood glucose was raised by more than $60 \mathrm{mg} / \mathrm{dl}(3.2 \mathrm{mmol} / 1)$, giving a greater than twofold rise of insulin when compared with the response elicited by intravenous glucose alone. Andersen et al. [3] performed a series of experiments with a glucose clamp technique which demonstrated the glucose-dependent nature of GIP-stimulated insulin release. They gave oral glucose to release endogenous GIP and showed that no augmentation of the ensuing insulin release occurred during the maintenance of euglycaemia. However, when blood glucose was allowed to rise by $20 \mathrm{mg} / \mathrm{dl}(1.1 \mathrm{mmol} / 1)$ then the response of insulin could be enhanced. The same group reported in 1979 [8] that an infusion of GIP to give plasma levels of around $500 \mathrm{pmol} / 1$ produced a fourfold increase of insulin when blood glucose was clamped at an elevation of $54 \mathrm{mg} / \mathrm{dl}(3 \mathrm{mmol} / 1)$. The same high level of GIP produced a sevenfold increase of insulin when a hyperglycaemia of $143 \mathrm{mg} / \mathrm{dl}$ $(8.0 \mathrm{mmol} / 1)$ over basal was maintained.

The results reported here are in broad agreement with those discussed above and show that, when blood glucose is raised by $2.0 \mathrm{mmol} / 1(36 \mathrm{mg} / \mathrm{dl})$ above basal and GIP is infused to produce plasma concentrations within the physiological range, then a threefold rise over basal of insulin could be produced.

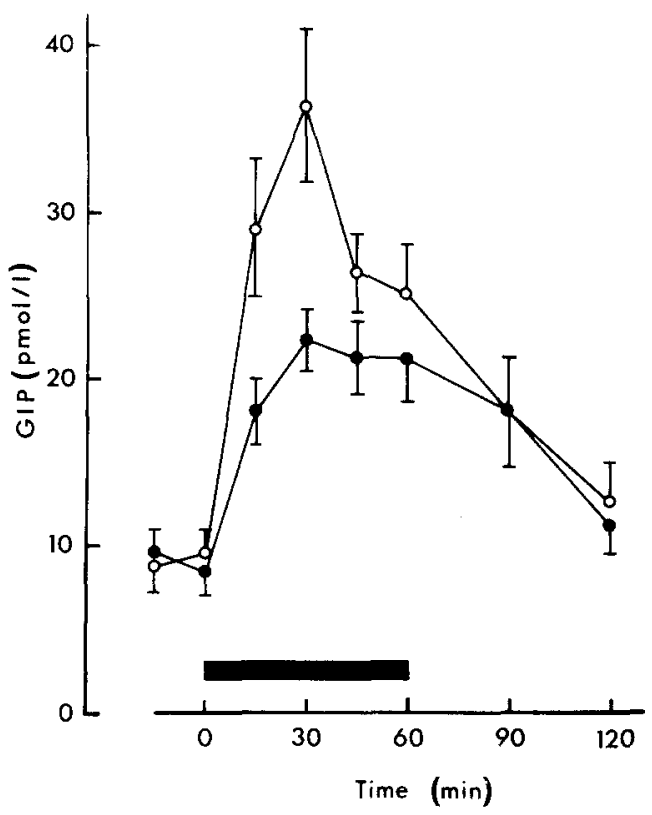

Fig. 2. GIP response (pmol/1, mean \pm SEM) in 12 subjects following $50 \mathrm{~g}$ oral glucose (C) or IV glucose + IV GIP $(O)$. Solid bar denotes duration of infusion (see text for details)

The hyperglycaemia produced in these subjects was comfortably in excess of the $20 \mathrm{mg} / \mathrm{dl}(1.1 \mathrm{mmol} / \mathrm{l}) \mathrm{in}$ crease of glucose proposed as the threshold for the insulinotropic action of GIP to become operative. However it is apparent from this investigation that the insulin response provoked by the infusion of GIP and glucose is only about one-third of that produced by the ingestion of the oral glucose load in spite of the similarity of the degree of hyperglycaemia observed. The insulinotropic effect of GIP (peak insulin 191.6 $\pm 30.9 \mathrm{pmol} / \mathrm{l}$ ) plus glucose could well be greater than that seen after intravenous glucose alone when the results of this study are compared with those of eight healthy volunteers of similar age and weight (peak glucose $6.4 \pm 0.3 \mathrm{mmol} / 1, \Delta$ glucose $2.4 \pm 0.2$, peak GIP $8.1 \pm 2.1 \mathrm{pmol} / 1, \Delta \mathrm{GIP} 0.5 \pm 1.8$, peak insulin $122.7 \pm 20 \mathrm{pmol} / 1, \Delta$ insulin $79 \pm 13$ ) (unpublished observations).

Without an agreed bioassay, it is conceivable that the porcine GIP used was not fully biologically active in man but indirect evidence from chromatography and parallelism studies suggest that the molecule is similar to that found in human jejunal tissue and circulating in the plasma. The disappearance half-time of the porcine GIP of $20.3 \mathrm{~min}$ was also similar to that found by Brown et al. [9] of $21 \mathrm{~min}$ and that found by Elahi et al. [8] of $20.4 \pm 2.37 \mathrm{~min}$. In addition, the administration of a low dose somatostatin infusion $\left(0.3 \mathrm{nmol} \mathrm{kg}^{-1} \mathbf{h}^{-1}\right)$ to six non-fasted patients with pancreatic apudoma, caused a suppression of endogenous GIP from a basal of $22.5 \pm 3 \mathrm{pmol} / 1$ to 9.8 
$\pm 2 \mathrm{pmol} / 1$ after $30 \mathrm{~min}$. When this data was plotted as a percentage of the GIP remaining against time, $50 \%$ had disappeared within $24 \mathrm{~min}$ (unpublished observation). Thus endogenous GIP was removed from the circulation with a similar time-course to the halflife of exogenous GIP. This further supports the similarity of the preparations used.

There are a number of differences in the experimental methods employed in this study and those reported earlier. Although the GIP infusion doses given by Elahi et al. [8] and the present authors were much the same, the plasma levels measured are disparate. We have consistently reported considerably lower fasting and post-prandial GIP concentrations $[5,10]$ and it is likely that differences in assay methodology, such as the use of standard curves bereft of GIP-free plasma, are responsible for this phenomenon. With regard to the potent insulin release reported in that paper, attention should be drawn to the size of the increment of blood glucose required to produce this $(8.0 \mathrm{mmol} / \mathrm{l})$ which would rarely be produced in subjects with normal glucose tolerance.

The use of procedures resulting in the endogenous release of GIP, reported by Andersen et al. [3], resulted in a slightly smaller enhancement of insulin when compared with the infusion experiment reported here, although the blood glucose levels in both studies were similarly elevated above basal. In this instance it is difficult to explore the effect of GIP on its own since clearly there may be potentiation by other gut factors, including neural influences, also stimulated by glucose ingestion and which may be insulinotropic in a glucose-dependent fashion.

We conclude from this study, and from the others $[2,3,8]$, that the insulin response to oral glucose has not yet been shown to be due to the action of GIP alone. The effect of GIP appears likely to be weak in individuals with normal glucose tolerance where a minimal degree of hyperglycaemia can be observed. It may be that it is only in the event of supranormal blood glucose levels that a compensatory insulin stimulating mechanism involving GIP becomes important. The reportedly augmented GIP concentrations seen in some Type 2 (non-insulin-dependent) diabetics [11] may well be the result of some such compensatory action.
Acknowledgments. This study was supported by the British Diabetic Association and the Wellcome Trust. SMW is an R. D. Lawrence Research Fellow of the British Diabetic Association. Gratitude is expressed to Professor J.C. Brown, University of British Columbia, Vancouver, Canada for the supply of pure porcine GIP.

\section{References}

1. Cleator IGM, Gourlay RH (1975) Release of immunoreactive gastric inhibitory polypeptide (IR-GIP) by oral ingestion of food substances. Am J Surg 13: 128-135

2. Dupre J, Ross SA, Watson D, Brown JC (1973) Stimulation of insulin secretion by gastric inhibitory polypeptide in man. $\mathbf{J}$ Clin Endocrinol 37:826 828

3. Andersen DK, Elahi D, Brown JC, Tobin JD, Andres R (1978) Oral glucose augmentation of insulin release. J Clin Invest 62: 152-161

4. Creutzfeldt W (1979) The incretin concept today. Diabetologia $16: 75-85$

5. Sarson DL, Bryant MG, Bloom SR (1980) A radioimmunoassay of gastric inhibitory polypeptide in human plasma. J Endocrinol $85: 487-496$

6. Holohan KW, Murphy RF, Flanagan RWJ, Buchanan KD, Elmore DT (1973) Enzymatic iodination of the histidyl residue of secretin: a radioimmunoassay of the hormone. Biochim Biophys Acta 322: 178-180

7. Alford FP, Bloom SR, Nabarro JDN (1977) Glucagon levels in normal and diabetic subjects: use of a specific immunoabsorbent for glucagon radioimmunoassay. Diabetologia 13: 1-6

8. Elahi D, Andersen DK, Brown JC, Debas HT, Herschcopf RJ, Raizes RS, Tobin J, Andres R (1979) Pancreatic alpha and beta cell responses to gastric inhibitory polypeptide in normal man during controlled glycaemia. Am J Physiol 237: E185-E191

9. Brown JC, Dryburgh JR, Ross SA, Dupre J (1975) Identification and actions of gastric inhibitory polypeptide. Rec Progr Horm Res $31: 487-532$

10. Besterman HS, Bloom SR, Sarson DL, Blackburn AM, Johnston DI, Patel HR, Stewart JS, Modigliani R, Guerin S, Mallinson CN (1978) Characteristic gut hormone profile in coeliac disease. Lancet 1:785-788

11. CrockettSE, Mazzaferri EL, Cataland S (1976) Gastric inhibitory polypeptide in maturity-onset diabetes mellitus. Diabetes 25:931-935

Received: 27 April 1981

and in revised form: 22 July 1981

Dr. S. R. Bloom

Department of Medicine

Royal Postgraduate Medical School

Du Cane Road

London W12 OHS, UK 